Cómo citar / How to cite: Molina Gómez, J. A., Uroz Rodríguez H. y Munera Martínez, J. A. 2020. Los mártires de Libisosa: origen, transformación y pervivencia de una tradición hagiográfica. Antigüedad y Cristianismo 37, 45-62. https:/ doi.org/10.6018/ayc. 457171

\title{
LOS MÁRTIRES DE LIBISOSA: ORIGEN, TRANSFORMACIÓN Y PERVIVENCIA DE UNA TRADICIÓN HAGIOGRÁFICA
}

\section{THE MARTYRS OF LIBISOSA: ORIGIN, TRANSFORMATION AND SURVIVAL OF A HAGIOGRAPHIC TRADITION}

\author{
José Antonio Molina Gómez \\ Universidad de Murcia, \\ Murcia, España \\ jamolgom@um.es
}

orcid.org/0000-0003-4675-0125

\author{
Héctor Uroz Rodríguez \\ Universidad de Murcia, \\ Murcia, España \\ hector.uroz@um.es \\ orcid.org/0000-0002-0140-1071
}

\author{
José Ángel Munera Martínez \\ CEIP Federico Mayor Zaragoza, \\ Albacete, España \\ angelmunera@gmail.com \\ orcid.org/ 0000-0002-0460-9273
}

Recibido: $13-9-2020$

Aceptado: 1-12-2020

\section{RESUMEN}

En el presente artículo los autores estudian las tradiciones hagiográficas sobre los mártires del siglo III Vicente y Leto, quienes murieron en Libisosa (Lezuza, Albacete). El estudio se centra en la relación entre tradiciones martirológicas, la evidencia arqueológica y las tradiciones locales. Escritores modernos como Higuera y Requena podrían haber usado fuentes antiguas para (re) escribir la historia de Vicente y Leto. De acuerdo con la tradición local ambos fueron ejecutados en un lugar llamado hoy en día Vallejo de los Santos/Mártires, en las inmediaciones de Lezuza, donde habría sido levantado un templo para rendirles culto.

Palabras clave: Mártires Vicente y Leto, Higuera, Bachiller Requena, Lezuza, Fuentes antiguas, Tradiciones locales, Hagiografía.

\begin{abstract}
In the following article, the authors study the hagiographic tradition of the Third Century Christian Martyrs Vicente and Leto, both of which died in Libisosa (Lezuza, Albacete). Said study shall focus upon the link between the matyrological tradition, archaeological evidence and local traditions. Modern writers such as Higuera or Requena may well have employed these ancient sources while (re)writing the history of Vicente and Leto. According to local tradition, both were executed in a place now called Vallejo de los Santos/Mártires, in the outskirts of Lezuza, where a temple would have been built for their worship.
\end{abstract}

Keywords: Martyrs Vicent and Leto, Higuera, Bachiller Requena, Lezuza, Ancient sources, Local traditions, Hagiography. 


\section{SUMARIO}

1. Vrbs antiqua fuit. 2. 2. La invención mozárabe de la tradición. 3. Invención, revisión y forja continua de una nueva tradición en la España de la Contrarreforma. 4. Pervivencia de la tradición en los albores de la modernidad. 5. Conclusiones.

\section{VRBS ANTIQUA FUIT}

En virtud de las excavaciones arqueológicas llevadas a cabo de forma sistemática desde 1996 en el "Cerro del Castillo" del municipio albaceteño de Lezuza' (Figura 1), no existen dudas sobre su identificación con la colonia Libisosa Foroaugustana con ius italicum mencionada por Plinio el Viejo (N.H. III, 25). Al mismo tiempo, dichas intervenciones han sacado a luz un asentamiento ibérico anterior, adscrito a la regio Oretania según la Geografía de Ptolomeo (II, 6, 58), que habría sido destruido definitivamente y de forma precipitada en el contexto de las guerras sertorianas (Uroz Rodríguez y Uroz Sáez 2014), razón por la cual su conservación y las fuentes para su conocimiento resultan excepcionales, y ha centrado buena parte de los esfuerzos de las últimas investigaciones ${ }^{2}$. Posiblemente, el mismo ejército romano que destruyó el oppidum levantaría de forma apresurada la muralla que, aun con reformas, se mantendría para todo el período romano (Uroz Sáez, Poveda y Márquez, 2006). Y entre dicha construcción y la fase colonial, tendríamos la primera "época oscura” de la historia del yacimiento, cuando Libisosa ostentaría la categoría jurídico-administrativa de forum (Poveda 2002), fosilizada en el cognomen. De esta fase apenas se han detectado huellas arqueológicas, aunque, quizá, sí nos

1 Las intervenciones arqueológicas en Libisosa, dirigidas en la actualidad por Héctor Uroz Rodríguez y José Antonio Molina Gómez junto a José Uroz Sáez, impulsor e iniciador de las excavaciones, se desarrollan en el marco de los programas de investigación e intervención sistemática del Servicio de Arqueología y Patrimonio de la Consejería de Cultura de Castilla-La Mancha, con la colaboración del Ayuntamiento de Lezuza, la Diputación Provincial de Albacete-Instituto de Estudios Albacetenses y las Universidades de Alicante y Murcia.

2 Vid. recientemente, con la bibliografía anterior: Uroz Rodríguez, 2020 han llegado algunos de sus protagonistas. Nos referimos a la inscripción funeraria de $L$. Cornelius salida a la luz con la remodelación de la "Casa de la Tercia" en 1989 y publicada por J. M. Abascal (1990, 45-49; Abascal y Sanz 1993, 24, 35), que, con el tiempo, hemos podido saber que fue recuperada originariamente en la vega del río Lezuza, a pocos metros de la ciudad (Uroz Sáez 2012, 105), y que representa el primer testimonio de un ciudadano romano en Libisosa. La inscripción se encuentra en la actualidad en el Centro Sociocultural Agripina de Lezuza (Figura 2), y su lectura es la siguiente:

$$
\begin{aligned}
& \text { L(ucius). Cornelius. C(ai) f(ilius). Ser [g(ia } \\
& h(i c) \cdot s(\text { itus }) \cdot e(s t) \\
& \text { Varisidia C(ai)f(ilia) Maxum [a rap] } \\
& \text { ta } \cdot \text { crudelibus. fa[tis] } \\
& \text { Cornelia. mater. se. [viva f(ecit?)] } \\
& \text { vos-venio }
\end{aligned}
$$

La adscripción del dedicante a la tribu Sergia (en vez de la Galeria, propia de la colonia ${ }^{3}$ ) parece asociar su llegada a época cesariana, y quizá podría servir como argumento para ubicar la etapa forum en ese momento. Pero lo que interesa de esta lápida en este trabajo, y a lo que volveremos más adelante, es el cognomen Maxima (con la nada extraña sustitución de la I por la $\mathrm{V}$ en la grafía) que ostenta el personaje femenino objeto de la dedicatoria, y cuyo nomen Varisidia parece denotar un origen

3 La adscripción a la tribu Galeria de los colonos de Libisosa, confirmada por algún hallazgo epigráfico en las excavaciones del foro (Uroz Sáez, 2012, fig. 21b), se conoce en virtud de la inscripción (CIL II, 4254) hallada en Tarragona con un ilustre libisosano convertido en flamen provincialis de la Citerior en época de Adriano (Alföldy, 1975, no 313). 


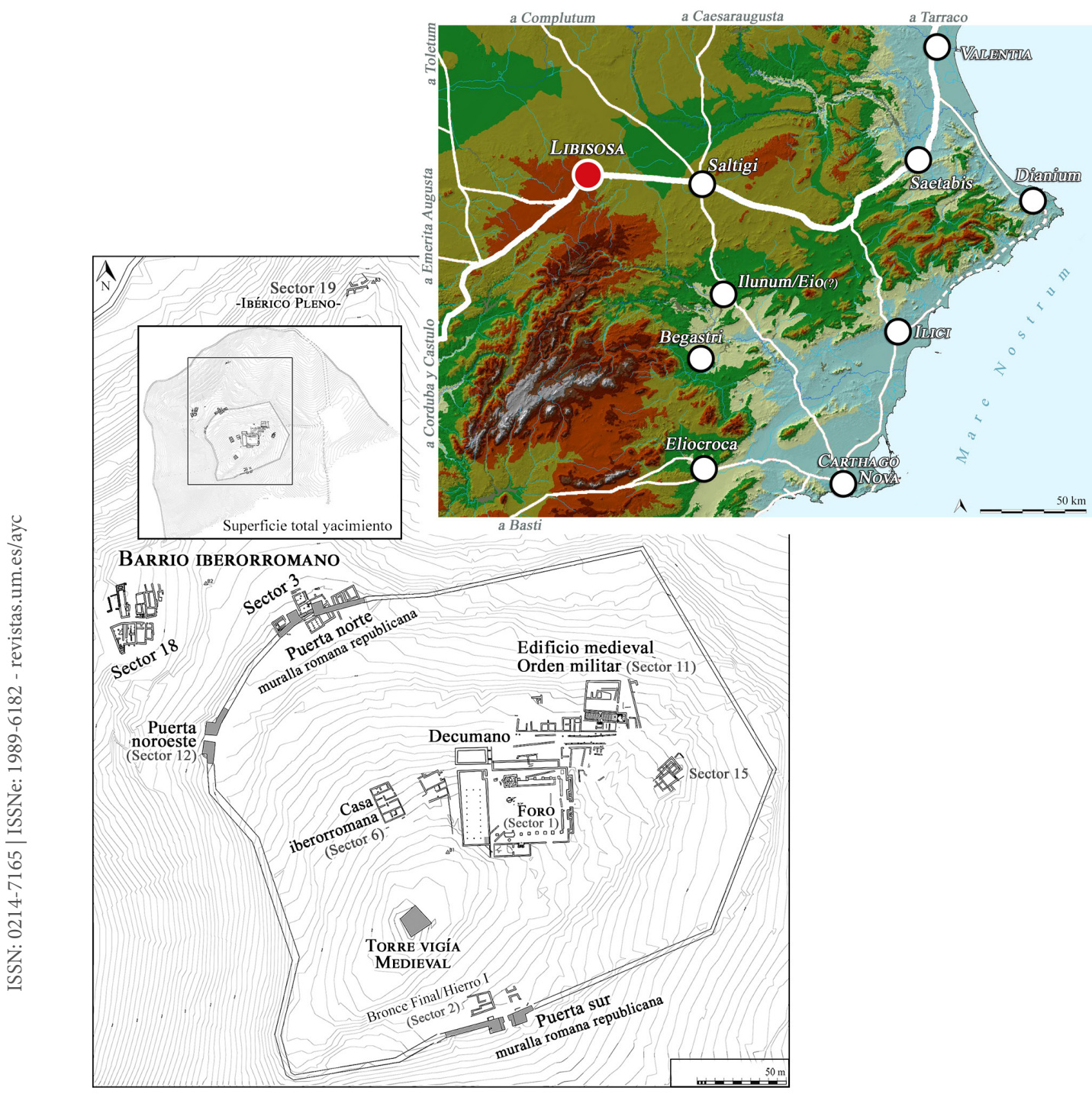

Figura 1. Situación de Libisosa en el sureste hispano respecto al viario romano y plano de la superficie excavada del yacimiento (elaboración propia).

itálico de la familia (Uroz Rodríguez y Velaza 2020, 310, n. 8).

En cambio, de la fase colonial contamos con no pocos vestigios de diversa índole, destacando el foro construido ad hoc en la parte más alta del cerro, el primer sector excavado del yacimiento (Uroz Sáez, Molina y Poveda 2002; Uroz Sáez 2012, 111-115). Sobre la mención de la colonia de Libisosa por Plinio, lo primero que debe tenerse en cuenta es que, para describir los conventos jurídicos, este autor, aun escribiendo en época de Vespasiano, se nutrió de fuentes de un momento anterior al cambio de Era, fundamentalmente de época augustea, como el censo de Marco Agripa del 12 a. C. (Beltrán Lloris 1999, 248-251, 258). La promoción colonial le habría sido otorgada a Libisosa por Augusto, posiblemente con ocasión de su tercer viaje a Hispania (15-13 a. 


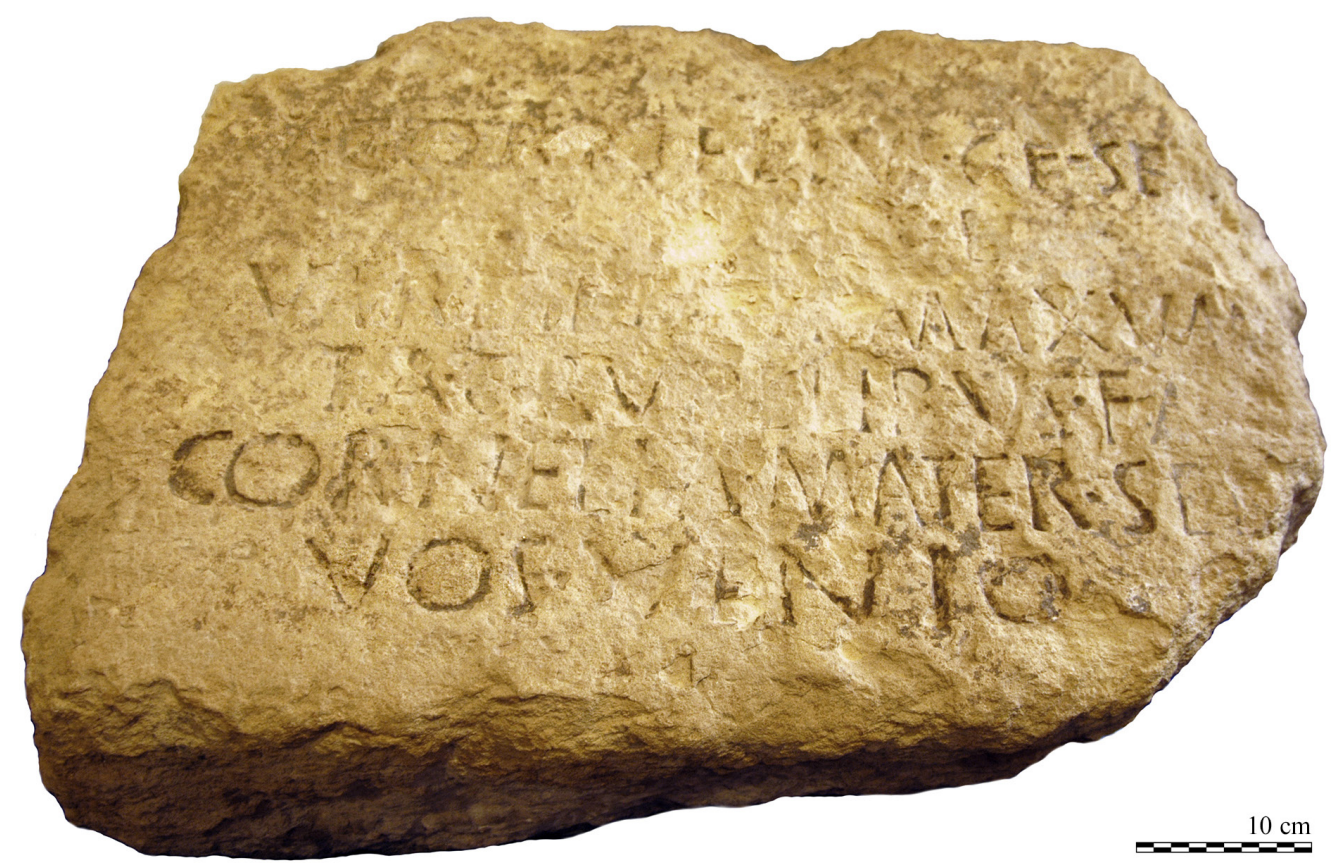

Figura 2. Inscripción funeraria recuperada en la vega del río Lezuza dedicada a un personaje femenino de cognomen Maxima (foto: Héctor Uroz).

C. $)^{4}$, añadiendo el ius italicum como incentivo para fijar a la población en un enclave de elevado valor geoestratégico. $\mathrm{Y}$ es que la ciudad se encontraba en estrecha relación con el control efectivo de las comunicaciones que unían el Sur con el Levante, y la Meseta con la actual costa murciana, lo que resultaba fundamental para garantizar el comercio y el desplazamiento de los ejércitos y los miembros de la administración pública (Uroz Sáez y Uroz Rodríguez 2016) (Figura 1). Se trata de la via Heraclea (Uroz Sáez y Poveda 2008, 145-148) o Camino de Aníbal (Sillières, 1999), recogida en los Vasos de Vicarello (CIL XI, 3281-3284: I: Libisosam; II, III y IV: Libisosa), el eje viario más importante durante las épocas ibérica y romana republicana, alguno de cuyos tramos todavía se conserva cerca de Lezuza. Los posteriores itinerarios de época imperial (Itinerario de Antonino, 446, 11: Libisosia; Anónimo de Rávena, IV, 44; 313, 14: Lebinosa), seguirán

4 Sobre la fecha de la deductio colonial de Libisosa, vid.: Uroz Sáez, 2012, 105 ss. dejando constancia del valor estratégico de la ciudad (Sanz, 1989; Carrasco, 2000), que será absolutamente determinante a lo largo de su historia. A su vez, otra importantísima vía conectaba Libisosa con el Mediterráneo desde época prerromana, la de Saltigi-Carthago Nova (Sillières 1982), que sería consolidada por Tiberio y reparada durante los ss. II-III d. C., y se convertiría en uno de los ejes de comunicación fundamentales durante la Edad Media. En época romana sirvió para estructurar todo el territorio circundante, en relación con el puerto de Carthago Nova y las ciudades de su conventus, y para el desplazamiento de las legiones y las mercancías.

La integración y la conexión con el mundo romano se ven seriamente afectadas con la crisis del sistema imperial y la progresiva ruralización. La Antigüedad Tardía supondría la segunda "época oscura" de Libisosa. Si su privilegiada relación con el viario resultó clave para el desarrollo de la ciudad a lo largo de las distintas épocas, cuando el centro de poder cambió (como en época visigoda), y las vías 
de comunicación entre la Meseta, Andalucía y Levante pierden peso, Lezuza parece desaparecer del mapa. Para este período se ha diferenciado entre la zona más claramente sudoriental en torno al Tolmo de Minateda (Hellín), la antigua Ilunum (Abad, Gutiérrez, Gamo y Cánovas 2020), que conocería su máximo esplendor entre los ss. VII y IX (Gutiérrez 2008), y otra zona, la del Júcar, los Llanos de la Mancha y Campo de Montiel que podría considerarse de transición y contacto entre Levante y la Meseta (Perlines y Hevia 2017). Nos encontramos, en todo caso, ante un mundo eminentemente rural (Gamo 1999), el cual, además, cae en un severo mutismo por parte de las fuentes literarias a partir del siglo IV d. C. No obstante, el proceso de transformación y la decadencia arquitectónica a partir del s. $\mathrm{V}$, se puede seguir, desde un punto de vista arqueológico, en la villa de Balazote (Sarabia 2012), la más cercana y mejor conocida del territorio libisosano, así como el nuevo paisaje rural que se irá consolidando en su entorno (Sarabia, e. p.). Las huellas materiales de las factorías altoimperiales (algunas herederas de otros centros tardorrepublicanos) del espacio inmediatamente circundante a Lezuza, por lo visto en la carta arqueológica del municipio, brillan por su ausencia. De este modo, junto al arquetípico poblamiento rural de la Antigüedad Tardía y la Alta Edad Media caracterizado por villas romanas señoriales que pudieron desarrollarse posteriormente en aldeas, tendría lugar también un fenómeno de despoblación de lugares y villas más periféricas peor comunicadas, así como el abandono del mantenimiento de las infraestructuras viarias, resultando un poblamiento más disperso aún de lo que era. Eso, sin duda, afectaría al tráfico de mercancías y a las actividades económicas, reducidas al autoconsumo y a la subsistencia. Paralelamente, en medio de un proceso de encastillamiento y ocupación de poblados en altura, la población residente recuperaría espacios encaramados y abruptos por su fácil defensa, ligado en algún caso a un nuevo fenómeno de monumentalización. $\mathrm{Al}$ mismo tiempo, las formas y manifestaciones de la piedad religiosa se irían ruralizando y aislándose al mismo ritmo, coincidiendo con el auge de pequeñas comunidades monásticas y reducidos grupos de anacoretas como sugieren las posibles manifestaciones de monacato rupestre el Alborajico y la cueva de la Camareta (Molina Gómez 2011, 49-65).

El modelo organizativo de poblamiento oscilaría entre el peso de las comunidades rurales organizadas en torno a fundus y villae, y el de comunidades de aspecto más urbano como el Tolmo de Minateda, que caería en la esfera visigoda como punta de lanza junto con Begastri (Jordán Montes, Molina y Zapata, 2011), para oponerse al poder bizantino en la Península y que luego habría de ser una de las ciudades del Pacto de Teodomiro ${ }^{5}$. Así y todo, conviviría en su territorio inmediato con un modelo de asentamientos rústicos de pequeñas dimensiones (Gutiérrez y Grau 2012), no tanto villae señoriales, en un universo de matices que se va desvelando por nuevas investigaciones en torno a la manera en que se articula el espacio suburbano y rural (Sarabia 2016; 2014). Para nuestro caso en concreto, se trata de los espacios geográficos que todavía en el siglo XVI autores como Hernando Colón en su Descripción y Cosmografía de España (Rodríguez de la Torre 1985, 25-26) describe como una zona de cerros, sabinares, y poblamiento disperso de casas de labranza y algunos núcleos más poblados, con una economía eminentemente de bosque y monte, ganado y cría de caballos, con tierras de labor y puntos de agua.

Tras el hiato y el vacío poblacional en la Alta Edad Media, el topónimo, ya como Lezuza, reaparece después de la reconquista en el siglo XIII. Correspondientes a la época bajomedieval se conservan en el yacimiento de Libisosa los restos arqueológicos de una torre vigía (Simón 2011, 212-214) que le han dado

5 Un resumen y puesta al día de los argumentos en torno a la localización de la sede episcopal de Eio/ Elo, que se ha debatido en las últimas décadas entre el mencionado Parque Arqueológico del municipio de Hellín, y El Monastil de Elda (Alicante), se encuentra en: Lorenzo de San Román (2016). 
nombre al cerro, pero también un complejo de carácter religioso, perteneciente a las órdenes militares (Uroz Sáez, Molina, Poveda y Márquez 2004, 190-191). El Bachiller Alonso de Requena, al que nos referiremos más adelante, escribe en el s. XVII que tras la conquista de Alcaraz en 1213 las tropas de Alfonso VIII habrían tomado el castillo de Lezuza. En 1411 existe un intento de aumentar o retener la población en la zona, eximiendo Alcaraz de tributos a todos los vecinos que quieran vivir en el cerro, junto a la torre (Petrel 1978, 72). La localidad se verá también involucrada en los conflictos entre el marquesado de Villena y los Trastámara, pero será con el reinado de los Reyes Católicos, y durante todo el siglo XVI, cuando Lezuza experimentará un crecimiento con la concesión de la categoría de villa, afirmándose el asentamiento en el llano, en torno a la nueva iglesia parroquial de Santa María de la Asunción, erigida, en parte, con los restos de la antigua ciudad romana.

Cuando Juan Antonio de Estrada publica su Población General de España en 1747, $\mathrm{y}$ en su segundo tomo describe Lezuza, Chinchilla, Tobarra y Almansa, arroja una imagen rural con producción de trigo, caza, aves, ganado, pesca y cría de caballos. Para el caso concreto de Lezuza el autor consigna que la zona produce pan, madera y esparto (Rodríguez de la Torre 1985, 69-70). Todavía en las Relaciones del Cardenal Lorenzana se habla de la ausencia de industria y del papel preponderante de la agricultura en Lezuza, con cultivos de cáñamos, trigo, cebada, panijos y legumbres, además de criadillas, habichuelas y hortalizas. Asimismo, hay membrillares, guindales y ciruelos (Munera Martínez 2014, 22-23). En medio de este antiguo proceso de dispersión, los restos de edificios que aún estuvieran en pie (como, posiblemente, el de las órdenes militares o el foro) se emplearían como puntos de abastecimiento de piedra o se podrían haber usado por monjes solitarios que buscaran en las ruinas algún tipo de refugio siguiendo los populares modelos anacoréticos visibles desde finales de la Antigüedad a los comienzos de la era moderna (Peña Velasco y Molina Gómez 2014, 225-263). Ello crearía, sin duda, un nuevo modo de tradición asociado a un remoto pasado legendarizado en medio de un contexto de disgregación de la población y de condiciones materiales marcadas por el autoconsumo y la economía de subsistencia.

\section{LA INVENCIÓN MOZÁRABE DE LA TRADICIÓN}

La llegada de la ocupación árabe provocaría que estas zonas, rurales de bosque y monte, fueran de facto zonas de repliegue para la población local que no sin ciertas prevenciones podríamos calificar de mozárabe. Aunque no se puede dar por cierta una división étnica, estudios actuales parecen avalar la hipótesis de población resiliente y retardataria en estas zonas por las que la dominación árabe sentía menos interés (de hecho, en la elaboración de la Carta arqueológica del municipio de Lezuza, no se encontraron materiales islámicos). Estos grupos humanos conservarían un tipo de memoria compartida, usos, costumbres y religión, que, ante la ausencia de estructuras estatales jerarquizadas, pervivirán y generarán sus modelos sociales a partir de la tradición superviviente, la cual podría desempeñar incluso un modelo identitario compartido. Aquí es donde jugarán un papel importante las tradiciones legendarizadas de las visitas de Pablo y los Varones Apostólicos, relatos fabulosos de santos que se apoyarían en los restos materiales todavía visibles y en las tradiciones orales que aún no se hubieran extinguido. Esta pervivencia de elementos preárabes sostenidos por la población de repliegue (Petrel 2011), podría haberse dado, de manera particular, en Libisosa, donde está documentada en el año 1411 una ermita, al parecer construida sobre una mezquita o un templo mozárabe, consagrado a la virgen Luciana, Luciosia o Luciosiana, y que se ha puesto en relación con Juno Lucina, diosa protectora de los partos, a la que habría estado consagrada en época romana, según la 


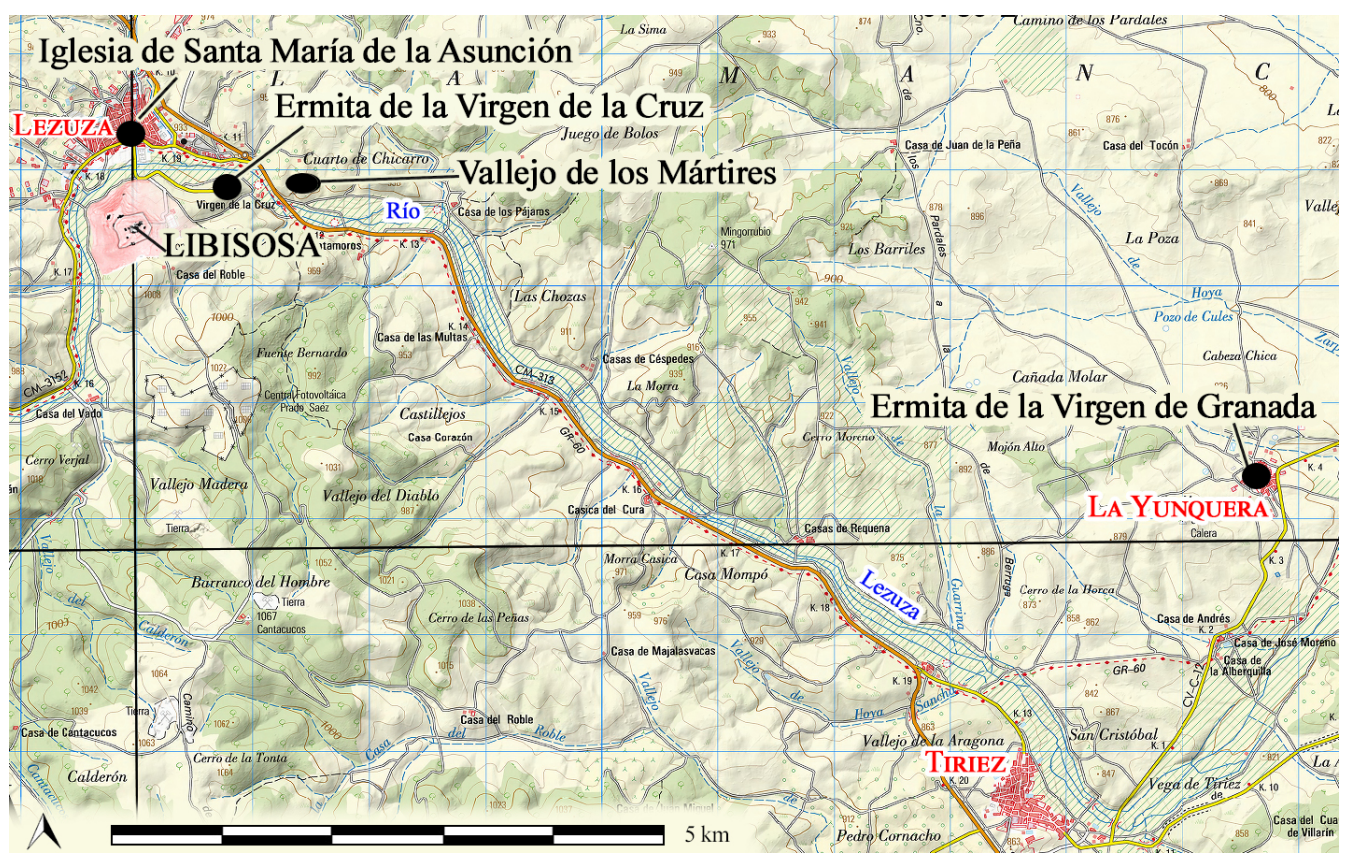

Figura 3. Plano del municipio de Lezuza con ubicación de los lugares de culto y el Vallejo de los Mártires (elaboración propia).

tradición, junto al dios Hércules. La ermita de La Yunquera de la Calzada, en el municipio de Lezuza, tiene una inscripción escrita a modo de epigrama que menciona a los mártires y que el Cardenal Lorenzana recoge en el siglo XVIII (Sánchez González 1991, 19), y sobre la que tendremos ocasión de volver, y en la que, no por casualidad, aparece, de nuevo, la figura de Hércules, como héroe fundador.

A esta ermita se le ha de unir el prometedor topónimo de Vallejo de los Mártires o de los Santos (Figura 3), paraje de Lezuza donde se dice que fueron ejecutados supuestamente los santos Vicente y Leto, en cuya memoria se habría consagrado una iglesia por parte del obispo de Cartagena, Marcelo de Laminio y Egila de Valeria. Aun aceptando lo fabuloso de la tradición, queda el topónimo como prueba de una tradición persistente en virtud de la cual aquellos lugares estaban vinculados al culto cristiano preárabe (Petrel 2011, 370371). Pero, además, en la carta arqueológica depositada en el Ayuntamiento de Lezuza en 2007, en función de los restos allí encontrados y las características del lugar, se propuso la existencia de un asentamiento agrícola de época romana, probablemente una villa que explotaría las tierras más fértiles de esta zona cercana a la ciudad romana de Libisosa.

La leyenda de los santos Vicente y Leto está vinculada a otras tradiciones más antiguas, en concreto al culto martirial de San Vicente, que posteriormente se transformaría a través de un proceso de duplicación dando lugar a un hermano gemelo llamado Leto. De manera que, antes de su popularización por fuentes historiográficas modernas, fue conocido en ambientes mozárabes: "En los calendarios del siglo $\mathrm{X}$, conservados en la biblioteca del monasterio de El Escorial, se reproduce nuevamente la festividad de los mártires abulenses. En el Códice Vigiliano (ms. d. I. 2), redactado en el año 976, se sigue manteniendo la celebración hispánica del 28 de octubre (28. V. Sci. uice(n)ti et sabine), al igual que en el Calendario Emilianense (ms. I. 1, redactado en el año 984): Sci. uicenti et sabine. En ambos textos se reproducen los mártires celebrados 
habitualmente por la liturgia hispánica anterior al siglo XI, pero surgen algunas novedades interesantes en cuanto a la duplicación de algunos santos relacionados con San Vicente de Zaragoza o con el mártir abulense. Así, además de la festividad destinada a San Vicente levita (22 de enero), se crea en estos códices, para el día 1 de septiembre, la fiesta de San Vicente y San Leto (Sci. uincenti et leti), supuestos mártires de origen africano hispanizados en el mundo mozárabe, considerados hermanos gemelos nacidos en Toledo. En este sentido, la duplicación de mártires a partir de un modelo original será una constante en la hagiografía medieval, al igual que el intento, también mozárabe, por inundar de hagiotopónimos relacionados con el martirologio y los calendarios aquellos lugares del norte de la península en los que se hacía necesario adjudicar un santo a cualquier núcleo de población o a los antiguos espacios cultuales paganos" (Ferrer García 2008, 15).

\section{INVENCIÓN, REVISIÓN Y FORJA CONTINUA DE UNA NUEVA TRADICIÓN EN LA ESPAÑA DE LA Contrarreforma}

Las historias sagradas y pías fabulaciones de la contrarreforma y de la monarquía católica encontrarían el terreno abonado para que tomaran forma las creaciones que habrían de aparecer en cultos martiriales y cronicones a partir del siglo XVI. En Lezuza, la existencia de restos arqueológicos reales ofrecía el marco material e histórico para la redacción de los primeros textos que recreaban la muerte de los mártires Vicente y Leto. La revitalización de la tradición corrió a cargo del Padre Román de la Higuera, quien seguiría fuentes variopintas para reescribir la historia de Vicente y Leto, cuyo lugar exacto de ejecución no lo revelaba el Martirologio Romano. Así, Higuera forjó la especie según la cual Vicente y Leto habrían sufrido martirio en Lezuza, apoyándose para ello en el cronicón de Dextro y en el cronista Julián Pérez. Una carta de Silo a Cixila de Toledo mencionaba a los hermanos mártires.
El arzobispo de Toledo, Bernardo de Sandoval y Rojas, se encargó de que la historia se hiciera llegar a las autoridades locales de la ciudad en 1595, quienes mandaron celebrar la fiesta y procesión anual en su honor (Olds $2015,184)$. Esta versión de la muerte de los mártires venía también corroborada por dos breviarios manuscritos sevillanos y un santoral portugués de comienzos del siglo XVI descubiertos en el siglo siguiente. El método de Higuera consistía en usar cuantas evidencias documentales tuviera acceso, a través tanto de correspondencia con informantes locales como de su propia documentación. Esta amalgama de manuscritos inéditos, que para la escala de la época podrían haber pasado como fiables, más el recurso a las tradiciones locales, sacaron en el siglo XVI a muchos santos de la oscuridad (Olds 2015, 254-255). Las élites locales estaban interesadas en la recuperación de su peculiar visión de la memoria histórica, pero no era poco el interés que mostraban los predicadores y pastores de almas. El hecho es que la presencia de los mártires de Lezuza en la tradición manuscrita era notable y lo bastante significativa para que Román de la Higuera primero, y Alonso Requena después, lo tuvieran en cuenta. Dicha tradición letrada se mezclaría sin duda con la memoria popular que hablaba del Valle (o Vallejo) de los Mártires. De ahí a la identificación de los santos locales con los hermanos Vicente y Leto solo había que dar un paso. A principios del siglo XVII, y antes de la publicación del libro de Requena, la noticia erudita traída por Román de la Higuera se había extendido ya por Lezuza. Es interesante a este respecto una relación del Libro $1^{\circ}$ de Fábrica de la parroquial que hace el cura doctor $\mathrm{D}$. Juan de Buendía en 1612. En ella se menciona a San Pablo, a San Vicente y a San Leto y como origen de la información alude a "un santoral antiquísimo en el monasterio de Predicadores de San Pablo de Cuenca, y del catálogo de Juliano Arcipreste, y del martirologio Romano Reformado y del Breviario Toledano". Continúa diciendo que esta relación la envió a Lezuza "el padre Gerónimo Romano de la Higuera 
de Belmonte a 20 de septiembre de 1600", para concluir que de los santos Vicente y Leto también "hace mención Silo, rey de Oviedo, en la carta que escribió a Cixila (?) Arzobispo de Toledo, desde Pravia a 24 de febrero de 815 " (García-Saúco 1991, 185-188).

Cuando a mediados del siglo XVII el Bachiller Alonso Requena, presbítero nacido en Lezuza, redactó la historia de los santos Vicente y Leto junto con la visita de San Pablo, empleó el método de Higuera, sirviéndose igualmente de las tradiciones preexistentes y de la pesquisa de manuscritos y el trato con informadores locales (Olds 2015, 255), e incluso la documentación epigráfica que estuviera disponible. Ello explicaría que en La Venida del Apóstol S. Pablo a España se mencionara, igual que antes había hecho Juan Buendía, a una mujer llamada Máxima (Requena 2015, 109) como la persona gracias a la cual se localiza el lugar de la ejecución de los santos, en un lugar cuyo hagiotopónimo es el Valle de los Mártires. La historia es digna de la mejor tradición de la inventio en hagiografía. Una matrona llamada Máxima se había dedicado a la vida consagrada, y su devoción la lleva a rogar a Dios que se le dé a conocer el lugar exacto donde están las reliquias de los mártires, cosa que finamente le es revelada por los mismos Vicente y Leto: porque estando Máxima una noche velando, le aparecieron dos mancebos de una edad, como hermanos de un vientre, y nacidos en un hora, vestidos con vestiduras rozagantes, con coronas en las cabezas, y con ellos un escuadrón de santos de edad venerable, con aspecto $y$ vestiduras que se hacían reverenciar. Rodearon los Santos Mártires y vueltos a la doncella, le dijeron: Máxima, digna de toda reverencia, está en vela, mira no te venza el sueño, porque tú sola has sido juzgada por merecedora que conozcas a los que siempre has reverenciado. Los que ves, somos Vicencio, y Leto, soldados de Dios que con su favor quedamos vencedores, los cuales en tiempos pasados en este templo, que fue consagrado por los gentiles, y ensuciado con la abominación de los demonios, más al presente por la virtud de Dios dedicado a nuestras victorias, y consagrado por Graciano, do reposamos aquí en nuestras cenizas (Requena 2015, 109-110).

Tras la milagrosa aparición, Requena habla del establecimiento del culto a los mártires y que este se mantuvo en el lugar elegido hasta que se diluyó en parte la memoria del lugar exacto donde los santos se encontraban, si bien, apelando a la tradición, nunca se habría perdido la memoria según la cual allí habría habido un lugar de martirio: los fieles, así de Lezuza, como de la comarca, juntos, con deseo de hacer algún servicio a Dios, y a los Santos Mártires, dice su Historia, que dieron sepultura a las sagradas cenizas donde acudían de diversas partes a pedir remedio a Dios de sus necesidades, por la intercesión destos Santos, continuándose esta devoción por muchos años, hasta que con las persecuciones se perdió el conocimiento de donde estaban, aunque nunca se perdió de haber padecido en este lugar (Requena 2015, 121-122). Además, en el Vallejo de los Mártires existió y fue visible durante años una cruz, actualmente desaparecida. Antiguamente se hacían procesiones coincidiendo con la supuesta fecha del martirio, primero de septiembre. En este lugar se encuentran todavía a ras de tierra restos de cerámica y teja romana (pertenecientes a la villa romana identificada en la prospección de la carta arqueológica municipal), y allí mismo el bachiller Requena señala en 1647 la existencia de una pared perteneciente al templo.

Apoyándose en la autoridad y crédito que le merecen los cronicones que apuntan al paraje del Vallejo de los Mártires o de los Santos, y en el Padre Jerónimo Román de la Higuera, que ve en el lugar el antiguo foro, pero sobre todo sirviéndose de la tradición local, acaba estableciendo que allí mismo tuvieron lugar las ejecuciones, la incineración de los cadáveres y el establecimiento de su culto a juzgar por paredes en pie y ruinas que deberían de haber pertenecido al complejo cultual. Hoy se llama este Vallejo, el Vallejo de los Santos, conservando siempre este nombre; $y$ ha sido $y$ es tradición que allífueron martirizados, la cual 
memoria y tradición (que como dice un autor, es digna de veneración, y respeto) hasta los tiempos presentes, se ha conservado (Requena 2015, 114). Aquí Requena se permite alejarse un tanto del Padre Román de la Higuera, el cual quería identificar el lugar de la ejecución con la ermita de Santa Lucina, mientras que Requena, natural de Lezuza y conocedor de las tradiciones locales, se inclinaba por el mencionado Valle de los Mártires (Requena 2015, 140-141). Pero además se da la circunstancia, como se ha dicho, que en la epigrafía local de principios del s. I d. C. se conocen dos personajes femeninos pertenecientes a la Gens Maxuma/Maxima: el de la inscripción ya aludida al principio de este trabajo, y una segunda conservada en el Museo Arqueológico de Murcia (Poveda 2016, 601602). Y que, además, los testimonios directos de su conocimiento epigráfico se remontan al siglo XIX: una carta del vecino Braulio López de 1874 (citada en Abascal y Gamo 1993, 23 26) y unos apuntes históricos de Juan Albacete de 1873 (Agüera 2003, 30-31). Si como se ha dicho muchas veces, la obra de Requena es fabulosa y se apoya sobre tradiciones inventadas, cabe preguntarse de dónde sabían los falsarios en el siglo XVII que existía una gens Máxima en la Libisosa del siglo I d. C. Tan posible es que la inspiración se hallase en testimonios epigráficos similares conocidos en la época, y ocultos para eruditos posteriores, como que una matrona del mismo nombre pusiera en marcha un culto martirial (fuera o no dedicado a Vicente y Leto). Y, en todo caso, no resulta forzoso reconocer que se ha deslizado un dato completamente verosímil y probablemente histórico en la leyenda de estos mártires.

La tradición, una vez puesta por escrito, pasó a ilustrar de manera programática las pinturas murales de la iglesia parroquial. La memoria de los mártires de Lezuza se popularizó rápidamente merced a la historiografía moderna, convirtiéndose en un elemento identitario de la ciudad, hasta tal punto que en el siglo XIX un autor anónimo (probablemente un maestro) escribió una novela histórica dedicada a los santos según manuscrito recientemente hallado. En el siglo XIX, y antes de la fecha de la novela histórica (hacia 1888), se publica el Diccionario de Pascual Madoz (1845-1850). En él se refiere el martirio de Vicente y de Leto, así como la venida de San Pablo. Por lo tanto, la memoria colectiva estaba impregnada totalmente de estos acontecimientos (Madoz 1847, 274-275).

Además, una inscripción en honor de Marco Aurelio por los colonos de Libisosa habría servido de improvisado púlpito, según las leyendas de las que se hacen eco los autores de los cronicones, para una predicación de San Pablo. En época de Constantino se habría consagrado la iglesia del s. IV que sustituía a la del siglo anterior. El mismo emperador habría visitado Libisosa (según dicha tradición transmitida por Requena) y la habría honrado con generosas aportaciones. La inscripción, conocida desde hace tiempo (CIL II, 3234), se fecha entre el 166 y 167 d. C. (Abascal 1990, 43-44; Abascal y Sanz 1993, 23):

Imp(eratori) Caesar(i) d[i]vi Ant[o]
[nini] filio divi Ha
driani nepoti d[i]
vi Traiani Parth(ici) pronep(oti)
Nervae abnepoti
M(arco) Aurelio Antonin[o]
Aug(usto) Armeniaco p(ontifici) m(aximo)
t(ribunicia) p(otestate) XX imp(eratori)
[III] co(n)s(uli) III
coloni(a) Libisosanoru[m]

Esta inscripción, siguiendo el relato de Ambrosio de Morales $(1574,303)$ la publicó Requena junto a la información de que habría aparecido unida a una escultura de mármol junto a la ermita. La piedra se reutilizó un tiempo en el claustro de la iglesia parroquial, y en 1767 fue empotrada en su ubicación actual (Figura 4), en el ángulo exterior que da a la plaza de la contigua Casa de la Tercia, según detalla D. Braulio López en su citada 
carta de 1874, dirigida a D. Pedro Cebrián, de Chinchilla (Abascal y Sanz 1993, 23). Ceán Bermúdez (1832, 86), quien la transcribe, comenta que había sido trasladada a Alcaraz, cosa que niega Amador de los Ríos (1912, 676). La escultura, actualmente en paradero desconocido, se habría perdido, según Amador (1912, 676-680), como consecuencia de las obras de ampliación, en el s. XVIII, de la iglesia, momento en el que también se habría recortado la piedra de la inscripción, para su reutilización, perdiendo así algunas letras.

En todo caso, la historia de la ejecución de los santos se relaciona con el paraje de

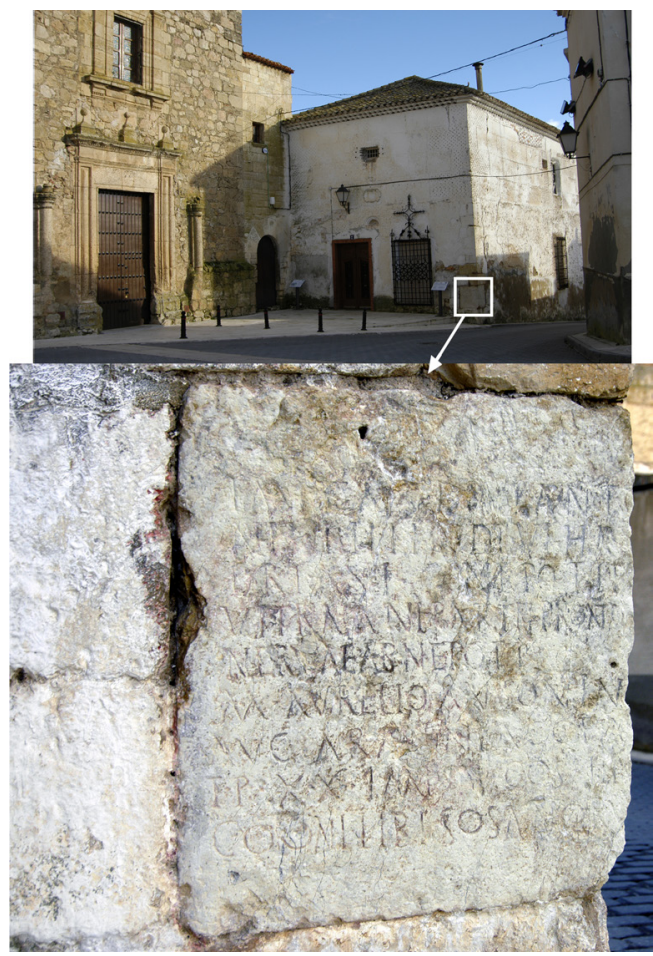

Figura 4. Pedestal de estatua con dedicatoria de los colonos de Libisosa a Marco Aurelio, reutilizada en la Casa de la Tercia, junto a la parroquia de Santa María de la Asunción (fotos: Héctor Uroz).

Lezuza denominado el Valle de los Mártires, más allá de si las construcciones y paredes de las que se habla hubiesen formado parte de un templo cristiano (o martyrium) dedicado a su memoria, o de una hipotética villa romana anterior, constatada en la prospección arqueológica. El Bachiller Alonso de Requena Aragón era presbítero natural de la ciudad y presumiblemente conoce no solo las tradiciones aludidas, sino que, además, cuando escribe su libro en 1647, puede situar dichas tradiciones en sus supuestos escenarios históricos. Debido a lo dudoso de las fuentes empleadas la obra nunca gozó de aceptación entre los círculos de historiadores considerados serios y sí en cambio de popularidad, no tanto por su mérito literario, que sin duda lo tenía, como por hacerse eco de una tradición legendaria pública y notoria. Desgraciadamente, solo por el hecho de haber sido puesta en tela de juicio la veracidad científica de los datos que aporta, la obra ha merecido un juicio severo desde el siglo XIX hasta la actualidad, como se resume en las palabras de F. Fuster: "No obstante a pesar de la gran curiosidad que despierta este libro, y la amenidad de su lectura por el estilo sencillo y natural, hay que decir que las fuentes en las que basa sus peregrinas teorías históricas no merecen gran fe, por estar basadas en los falsos cronicones, y por lo tanto este libro entra más bien entre los raros y curiosos que entre los verdaderamente científicos" (Fuster 2001, 48). Sin embargo, la obra gozó del favor popular y el Padre Juan de Aguilera la alabó considerando que el autor "era noticioso y universal, así en Historia como en su profesión de la Jurisprudencia y (...) en las letras divinas y Sagrada Teología” (según Rodríguez de la Torre, 1985, 21).

Otro gran elemento de importancia en la pervivencia de la tradición es el gran conjunto artístico que constituye la propia iglesia parroquial de Nuestra Señora de la Asunción. Entre el material suntuario que durante el siglo XVI estaba en poder de la parroquia, hay que citar la presencia de bordados en materiales nobles y bordados rojos, que más allá de su uso litúrgico para las fiestas de Cristo y la Virgen, también se empleaban en otras dedicadas a los apóstoles San Pedro y San Pablo, así como a los santos mártires Vicente y Leto (Pérez Sánchez 1998, 128-129, nota 19). La iglesia 


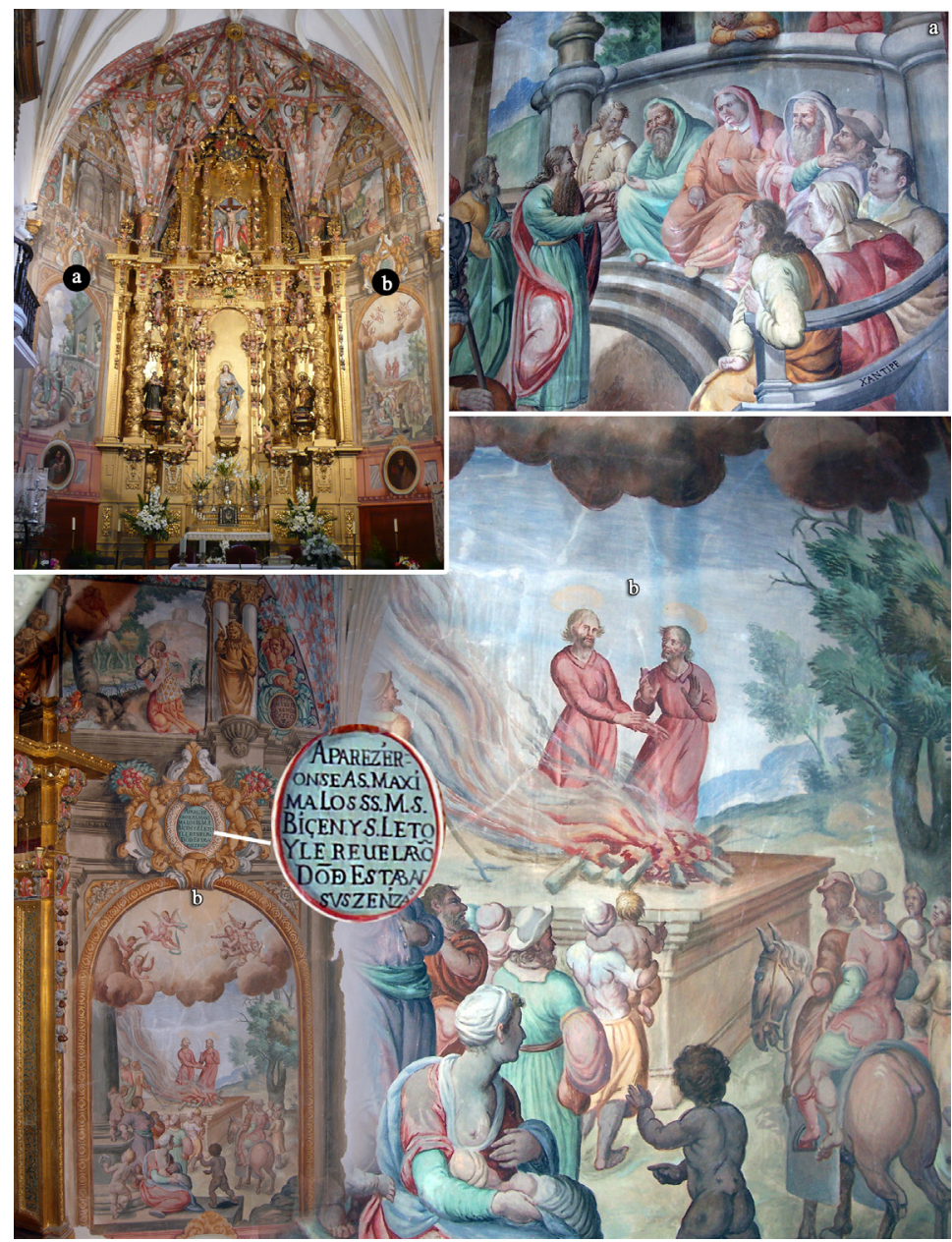

Figura 5. Retablo de la Iglesia de Santa María de la Asunción con la predicación de San Pablo (a) y con los mártires y detalle de la inscripción (b) (fotos: J. Ángel Munera).

es de gran interés histórico y artístico por sí misma (Lara Blázquez y Masa Cabrero 1990, 262-263; García-Saúco, Sánchez y Santamaría 1999, 162-164). Y su programa pictórico es una transcripción exacta del relato que ofrece Alonso Requena, incluyendo detalles aparentemente anecdóticos como el uso de la inscripción de Marco Aurelio como pedestal para la predicación del Apóstol, o los detalles topográficos tan exactos al pintar el escenario de la muerte de los Mártires que permite reconocer perfectamente el paraje del Vallejo de los Santos. El retablo de la iglesia, obra del escultor Josep Moller y del pintor Pedro
Guzmán es de finales del siglo XVII y en él se pueden ver, como decimos, un complejo pictórico en que se representa a San Pablo predicando en Libisosa, así como el martirio de Vicente y Leto, es decir un arco cronológico que va desde comienzos de la segunda mitad del siglo I hasta mediados del siglo III d. C. (Figura 5).

Las escenas del lateral izquierdo narran la predicación de San Pablo y la consagración del templo dedicado a los mártires. En el lateral derecho se representa en una hoguera el martirio de Vicente y Leto, así como la revelación a una cierta Santa Máxima del lugar 
donde se encuentran las cenizas de mártires, es decir, la inventio de las reliquias. Es conveniente reiterar que el paisaje de las pinturas muestra un claro y exacto conocimiento de la geografía local a la hora de identificar el lugar de culto de los mártires, pues contemplando dónde ha dispuesto el pintor el río y el castillo de la localidad, se puede localizar el paraje en el Vallejo de los Mártires, que es la ubicación que da precisamente Alonso Requena. De hecho, el programa pictórico del retablo de la iglesia se corresponde punto por punto con la relación del mencionado Requena en su Venida del Apóstol San Pablo a España, que es, en todo caso, de las primeras historias locales sobre la región, catalogada por el historiador Nicolás Antonio; y las menciones al viaje de Pablo y el martirio de sus santos se repite en las demás obras geográficas de la provincia de Albacete (Rodríguez de la Torre, 1985, 21).

Aunque Requena no llega a decir que Pablo predica sobre la famosa inscripción, un documento fechado en Lezuza el 27 de noviembre de 1723, perteneciente al Archivo Parroquial, hoy en el Obispado de Albacete, aparecen los libros de actas de la Cofradía de la Virgen Luciana desde 1631 hasta 1811. En este documento el vicario-visitador de Alcaraz, Licenciado don Francisco Barros, además de tomar nota de las cuentas que le rinde Don Juan de Frías, Mayordomo de la Cofradía de Nuestra Señora de Luciana, hace una visita a la referida ermita a la que encontró en bastante mal estado. Además de ordenar algunas reparaciones, quedan reflejados en el acta que levanta algunos datos de gran interés para la historia local. Escribe el vicario "que abiendo allado el indezente suelo que ai en ella" mandó que se hicieran las obras necesarias y "se allane $i$ en piedra conceda curiosidad dejando igual todo el suelo de la ermita..." También encarga al cura que repare la casa del ermitaño "que se alla arruinada" y que "haga los esfuerzos posibles para que recojan algunas limosnas y con ellas se repare dicha casa por si en algún tiempo hubiese ermitaño que resida en ella con lo que esto conduce para la mayor dezencia de la ermita y aumento del culto". La ermita debía rendir culto a San Ibo y allí habría una escultura del Santo, pues el vicario destaca "la especialísima devoción que se tiene en esta villa con San Ibo, que está en dicha ermita colocado". Concluye su visita diciendo que ha sido informado de "que una piedra que está dentro de esta ermita a la mano derecha de la puerta del mediodía y está fijada en el suelo" y según la tradición "el glorioso apóstol San Pablo predicó puesto de pie en ella". Este último párrafo explica la leyenda tan arraigada en Lezuza de la existencia de una piedra sobre la que predicó San Pablo, que con poco rigor histórico se habría confundido con la piedrapedestal a la que nos acabamos de referir, ubicada en la esquina de la casa de la Tercia.

\section{Pervivencia de la tradición en los ALBORES DE LA MODERNIDAD}

A mediados del siglo XVIII, con las nuevas ideas ilustradas, surgen en España varios intentos por conocer mejor la realidad social y económica del país. El método que se utiliza desde la Administración y desde la Iglesia es enviar a los ayuntamientos y a las parroquias, respectivamente, extensos cuestionarios que preguntaban por muy variados temas. Así, toda la información acumulada da lugar, entre otros estudios, a lo que hoy conocemos como Catastro del Marqués de la Ensenada, el Diccionario Geográfico-Histórico de Tomás López y las Relaciones del Cardenal Lorenzana. Estas últimas tienen particular interés para nosotros (Sánchez González 1991, 15-75; Munera Martínez 2014, 22-23). Don Francisco Antonio Lorenzana y Butrón (1722-1804), siendo Arzobispo de Toledo, más tarde Cardenal, se dirige a los curas de todas las parroquias del arzobispado con el fin de obtener datos de muy diversa índole y poder hacer un mapa del arzobispado, que completara el que en su momento dirigió el Cardenal Portocarrero. Hay que tener en cuenta que Lezuza perteneció al arzobispado de Toledo hasta la creación de la diócesis de 

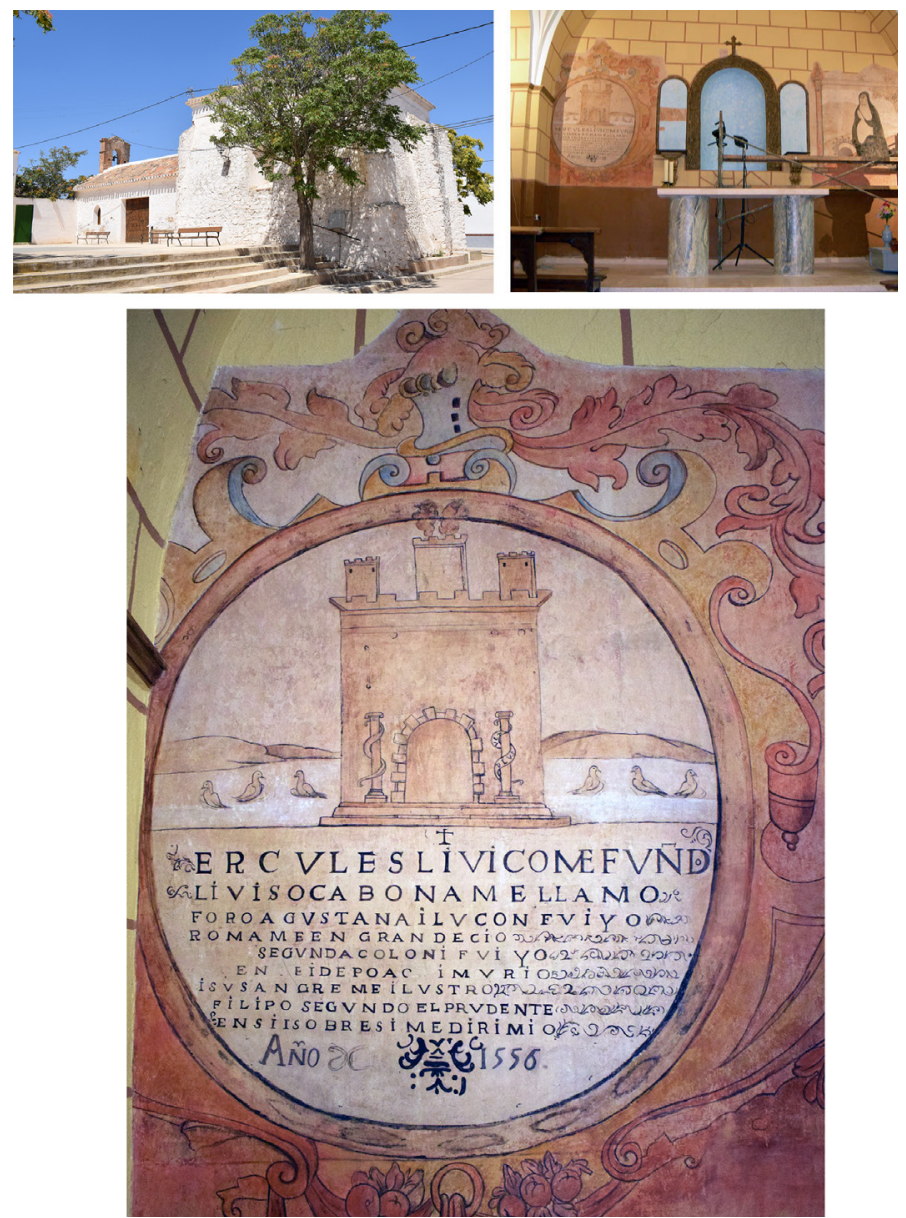

Figura 6. La ermita de la Virgen de la Granada en la Yunquera, con detalle de la inscripción de la pintura mural (fotos: J. Ángel Munera).

Albacete en 1949. El cuestionario constaba de catorce preguntas que eran contestadas por curas párrocos, vicarios o jueces eclesiásticos. Por lo que respecta a Lezuza, el cura que firma las respuestas a las catorce preguntas que formula el Cardenal Lorenzana es Don Juan Antonio Ferrer, fechadas el 23 de febrero de 1785. Los originales de las respuestas se guardaron en el Archivo Diocesano de Toledo. En el cuestionario (pregunta VII) se inquiere sobre la fundación de Lezuza, la antigua Libisosa y el cura menciona la ermita de la Yunquera y una inscripción en ella, en la que se leería: "Hércules Líbico me fundó, segunda colonia fui yo, Felipe Segundo me engrandeció,
Vizente y Leto aquí murió" (Munera Martínez 2014, 22-23). El texto completo, todavía in situ (Figura 6), dice más exactamente:

\section{HERCULES LIVICO ME FUNDÓ \\ LIVISOCA BONA ME LLAMO \\ FORO AUGUSTANA Y LUÇON FUI YO \\ VIZENTE Y LETO AQUÍ MURIÓ \\ I SU SANGRE ME ILUSTRÓ \\ FILIPO SEGUNDO EL PRUDENTE \\ EN SÍ Y SOBRE SÍ ME DIRIMIÓ \\ AÑO 1556}

En las repuestas del cura al cuestionario se aprecia la pervivencia de las leyendas de las 
predicaciones paulinas y la historia de los santos Vicente y Leto convertida ya en patrimonio identitario y memoria compartida del pueblo de Lezuza. La presencia de la memoria de los santos llega hasta el siglo XIX, como demostrará uno de nosotros (Munera Martínez) a través de un próximo estudio, edición y publicación de una novela histórica inédita, recientemente descubierta en Lezuza y que recrea la leyenda de Vicente y Leto, ilustrando así la importancia que como símbolo colectivo de la comunidad acabó alcanzando este culto.

\section{Conclusiones}

La leyenda de los mártires de Libisosa representa un caso interesante de pervivencia y transformación de la tradición. Nunca olvidados los orígenes prerromanos y romanos de la ciudad, la presencia de lugares y edificios vinculados al período cristiano primitivo debieron de permanecer relativamente fuertes y firmes durante la dominación árabe, al igual que en otros lugares de España donde se popularizaron a partir del siglo IX leyendas sobre los viajes de San Pablo, Varones Apostólicos, y tradiciones martiriales. El topónimo Valle de los Mártires sugiere que así fue. En época más tardía, el culto a San Vicente, revitalizado en época mozárabe, evolucionó y se duplicó dando lugar al de Vicente y Leto. En la tradición de manuscritos apócrifos que manejó el Padre Jerónimo Román de la Higuera se situaba Lezuza como lugar de la ejecución de dichos mártires. La popularización de este tipo de cultos durante la Contrarreforma dio lugar, en Lezuza, a un interés por Vicente y Leto desde el arzobispado de Toledo, y ocasionó la instauración de fiestas y procesiones de los mártires que estaban en relación con parajes locales como la ermita de Santa Luciana o el Vallejo de los Mártires. En el siglo XVII don Juan de Buendía, párroco de la iglesia, dejó por escrito en el libro primero de fábrica de la parroquia de la Asunción la historia de la ejecución de Vicente y Leto, por negarse a rendir culto a la diosa Lucina, así como el posterior descubrimiento de las reliquias por una matrona llamada Máxima (García-Saúco 1991, 185-188). Poco tiempo después, Alonso de Requena dio forma canónica a estas tradiciones normalizando lo que había leído en Higuera y otros autores, sumando aquellas noticias locales de las que tenía conocimiento, tanto de tradición oral como la naturaleza epigráfica; de manera que incorporó a su relato el paraje de los mártires e hizo aparecer a una matrona Máxima quizá en coincidencia con el cognomen conocido en la ciudad por epigrafía local, aunque afirmar esto es problemático dado que parece que las inscripciones donde aparece se (re) descubrieron posteriormente. No obstante, tal coincidencia no puede pasarse por alto. La popularidad que alcanzó el libro de Requena se debe no sólo al relato histórico en sí, sino a lo conocido de las tradiciones hagiográficas que menciona, y que dieron lugar posteriormente al conjunto pictórico de la iglesia parroquial, que es de hecho una transcripción fiel del libro del Bachiller.

Que la memoria colectiva de Lezuza aceptó el culto martirial como algo propio que estaba extendido y comportado por la mayoría de la población, se demuestra todavía en los momentos ya prácticamente modernos, en los que se hace la encuesta del Cardenal Lorenzana y se vuelve a tener constancia de la tradición de Leto y Vicente. Todavía en el siglo XIX la tradición estaba lo bastante viva como para inspirar una novela histórica. Dicha novela ha sido encontrada recientemente y está previsto su estudio y edición próximamente. No se trata, como resulta obvio, de demostrar si las tradiciones de Vicente y Leto fueron reales e históricas en sentido tradicional. La presencia de culto cristiano de época romana sí parece fuera de toda duda, así como la revitalización del culto durante época mozárabe, época en que la popularidad de Vicente y Leto fue notable. Por eso, no resulta extraño que manuscritos de diversa índole mencionaran Lezuza como lugar de los mártires. Durante la Contrarreforma las tradiciones confluyeron: 
el genio literario de Alonso de Requena y el talento artístico de Pedro Guzmán fueron semilla que prosperó sobre el fecundo suelo de la tradición histórica de Libisosa.

\section{BibLIOgRAFíA}

Abad, L., Gutiérrez, S., Gamo, B. y Cánovas, P. 2020. El yacimiento y el Parque Arqueológico de El Tolmo de Minateda (Hellín, Albacete). En Carretero, A. y Papí, C. (coords.), Actualidad de la investigación arqueológica en España I, 523-540. Madrid: Ministerio de Cultura y DeporteMuseo Arqueológico Nacional.

Abascal Palazón, J. M. 1990. Inscripciones romanas de la provincia de Albacete. Albacete: Instituto de Estudios Albacetenses.

Abascal Palazón, J. M., Sanz Gamo, R. 1993. Novedades de epigrafía romana en la provincia de Albacete. Al-Basit 33, 13-36.

Agüera Ros, J. C. 2003. Los apuntes de Don Juan Albacete. Un manuscrito histórico-artístico del siglo XIX. Murcia: Tabularium.

Alföldy, G. 1975. Die römischen Inschriften von Tarraco. Berlin: De Gruyter.

Amador De Los Ríos, R. 1912. Catálogo de los monumentos históricos de la provincia de Albacete, vol. 2. Albacete. http://simurg.bibliotecas.csic.es/viewer/image/CSIC001359447_V02F/5/

Beltrán Lloris, F. 1999. Municipium C.R., 'Oppidum C.R.'y 'Oppidum latinum' en la NH de Plinio: una revisión del problema desde la perspectiva hispana. En González, J. (ed.), Ciudades privilegiadas en el Occidente romano, 247-267. Sevilla: Diputación de Sevilla-Universidad de Sevilla.

Carrasco Serrano, G. 2000. En relación a las vías romanas y mansiones del territorio provincial de Albacete. Espacio, Tiempo y Forma. Historia Antigua 13, 455-468.

Ceán Bermúdez, J. A. 1832. Sumario de las Antigüedades Romanas que hay en España, en especial las pertenecientes a las Bellas Artes. Madrid: Imprenta de Don Miguel de Burgos.

Ferrer García, F. A. 2008. Literatura hagiográfica latina en torno a los mártires Vicente, Sabina y Cristeta de Ávila (siglos VII-XI). Hispania Sacra 60, 121, 9-46.

Fuster Ruiz, F. 2002. Datos para la historia de la historiografía de Albacete (1636-1845). En II Congreso de Historia de Albacete. Volumen IV: Edad Contemporánea, 47-62. Albacete: Instituto de Estudios Albacetenses.

Gamo Parras, B. 1999. La Antigüedad Tardía en la Provincia de Albacete. Albacete: Instituto de Estudios Albacetenses.

García-Saúco Beléndez, L. G. 1991. Heráldica municipal de la provincia de Albacete. Albacete: Instituto de Estudios Albacetenses.

García-Saúco Beléndez, L. G., Sánchez Ferrer, J. y Santamaría Conde, A. 1999. Arquitectura de la provincia de Albacete. Albacete: Junta de Comunidades de Castilla La Mancha.

Gutiérrez Lloret, S. 2008. Los orígenes de Tudmir y el Tolmo de Minateda (siglos VI-X). Regnum Murciae. Genesis y configuracion del reino de Murcia, 57-71. Murcia: Dirección General de Bellas Artes y Bienes Culturales.

Gutiérrez Lloret, S. y Grau Mira, I. 2012. El territorio tardoantiguo y altomedieval en el sureste de Hispania: Eio-Iyyuh como caso de estudio. En Caballero, L., Mateos, P. y Cordero, T. (eds.), Visigodos y omeyas, Anejos de AEspA 61, 171-198. Mérida: Instituto de Arqueología, CSIC http://rua.ua.es/dspace/handle/10045/24477

Jordán Montes, J. F., Molina Gómez, J. A. y Zapata Parra, J. A. 2011. La frontera entre visigodos y bizantinos en el Parque Regional de El Valle (ciudad de Murcia). Verdolay 13, 127-142. https://www.murciaturistica.es/webs/museos/publicaciones/PUBLICACION_es_238.pdf 
Lara Blázquez, P. y Masa Cabrero, F. 1990. Guía de Castilla La Mancha. Patrimonio Histórico. Toledo: Junta de Comunidades de Castilla La Mancha, Servicio de Publicaciones.

Lorenzo de San Román, R. 2016. Ecclesiae ilicitanae, qui et eiotanae, episcopus. Sobre la extensión y dualidad de la sede episcopal de Ilici en la Antigüedad tardía. Lucentum 35, 265-305. http:// dx.doi.org/10.14198/LVCENTVM2016.35.15.

Madoz, P. 1847. Diccionario Geográfico-Estadístico-Histórico de España y sus posesiones de ultramar. Tomo X. Madrid. http://www.bibliotecavirtualdeandalucia.es/catalogo/es/consulta/ registro.cmd? $\mathrm{id}=6353$

Molina Gómez, J. A. 2011. Los problemas para explicar la pervivencia del cristianismo durante la dominación musulmana en Murcia. Antigüedad y Cristianismo 28, 49-65. https://revistas. um.es/ayc/article/view/380241

Morales, Ambrosio de 1574. La coronica general de España. Alcalá de Henares: en casa de Iuan Iñiguez de Lequerica. http://www.liburuklik.euskadi.eus/handle/10771/28200

Munera Martínez, J. A. 2014. Lezuza en las relaciones del cardenal Lorenzana. Año 1785. Revista de Fiestas de Mayo del Ayuntamiento de Lezuza, 22-23. Lezuza: Ayuntamiento de Lezuza.

Olds, K. B. (2015). Forging the Past. Invented Histories in Counter-Reformatin Spain. New HavenLondon: Yale University Press.

Peña Velasco, M. C. y Molina Gómez, J. A. 2014. Ascetismo en imágenes: los ermitaños del Desierto del Sordo en el Siglo XVIII. Hispania Sacra 66, 225-263.

Pérez Sánchez, M. 1998. Un repertorio suntuario de singular interés: el ajuar litúrgico de la parroquia de Nuestra Señora de la Asunción de Lezuza (Albacete). Ensayos. Revista de la Facultad de Educación de Albacete 13, 119-145. https://dialnet.unirioja.es/descarga/ articulo/2292610.pdf

Perlines Benito, M. y Hevia Gómez, P. eds. 2017. La Meseta Sur entre la Tardía Antigüedad y la Alta Edad Media. Toledo. Junta de Comunidades de Castilla-La Mancha. Consejería de Educación, Cultura y Deportes.

Petrel Marín, A. 1978. Una ciudad castellana en los siglos XIV y XV (Alcaraz 1300-1475). Albacete: Instituto de Estudios Albacetenses. https://ruidera.uclm.es/xmlui/handle/10578/1022

Petrel Marín, A. 2011. ¿Pervivencias cristianas bajo dominio islámico en las sierras de Alcaraz y Segura? Antigüedad y Cristianismo 28, 355-388.

Poveda Navarro, A. M. 2002. Fora Hispania. La evidencia de Libisosa Forum Augustum (Lezuza, Albacete). Coninbriga 41, 538.

Poveda Navarro, A. M. 2016. De epigrafía libisosana. Identificación de una antigua inscripción con datos de la presencia de la Gens Maxuma. En Gamo, B. y Sanz Gamo, R. (coord.), Actas de la I Reunión Científica de Arqueología de Albacete, 595-608. Albacete: Instituto de Estudios Albacetenses.

Requena, Alonso de, 1647. Venida del Apóstol S. Pablo a España y predicación en ella y cómo estuvo en Libisosa. La Coruña (ed. facsímil de 2015 de la edición publicada en Madrid el año 1647).

Rodríguez de la Torre, F. 1985. Albacete en textos geográficos anteriores a la creación de la provincia. Albacete: Instituto de Estudios Albacetenses.

Sánchez González, R. 1991. El partido de Alcaraz a través de las relaciones del cardenal Lorenzana. Al-Basit. Revista de Estudios Albacetenses 28, 15-75.

Sanz Gamo, R. 1989. Fuentes escritas sobre la Colonia Libisosa Forum Augustana. Información Cultural Albacete 35, 312.

Sarabia, J. (e. p.). El paisaje rural tardoantiguo y altomedieval en torno a la antigua villa romana de Balazote (Albacete, España): detección y primeras reflexiones. En Tente, C. et al. (eds.), Early Medieval Countryside Archaeological Meetings. Oxford: Access Archaeology. 
Sarabia, J. 2016. El paisaje rural y suburbano de El Tolmo de Minateda (Hellín) durante la Antigüedad Tardía y la Alta Edad Media. En Gamo, B. y Sanz Gamo, R. (coord.), Actas de la I Reunión Científica de Arqueología de Albacete, 723-743. Albacete: Instituto de Estudios Albacetenses.

Sarabia, J. 2014. La transformación del paisaje rural tras la fundación del obispado de Eio-El Tolmo de Minateda (Hellín, Albacete, España): siglos V al IX d. C. Hortus Artium Medievalium 20, 216-231.

Sarabia, J. 2012. La villa de Balazote (Albacete). Un ejemplo de la vida en la campiña entre en Alto y el Bajo Imperio romano. Alicante: Universidad de Alicante.

Sillières, P. 1982. Une grande route romaine menant à Carthagène: la voie Saltigi-Carthago Nova. Madrider Mitteilungen 23, 247-257.

Sillières, P. 1999. Le Camino de Anibal, principal axe des communications entre l'Est et le Sud de l'Hispanie. En Centeno, R. M. S., García Bellido, M. P. y Mora G. (coords.), Rutas, ciudades y moneda en Hispania (Actas del II Encuentro Peninsular de Numismática Antigua, Porto, 1997), Anejos de AEspA 20, 239-250. Madrid: CSIC.

Simón García, J. L. 2011. Castillos y torres de Albacete. Albacete: Instituto de Estudios Albacetenses. Uroz Rodríguez, H. 2020. Libisosa: un "tesoro" para la investigación de Iberia e Hispania. En Carretero, A. y Papí, C. (coords.), Actualidad de la investigación arqueológica en España I, 2944. Madrid: Ministerio de Cultura y Deporte-Museo Arqueológico Nacional.

Uroz Rodríguez, H. y Uroz Sáez, J. 2014. La Libisosa iberorromana. Un contexto cerrado de -y por las guerras sertorianas". En Sala, F. y Moratalla, J. (eds.), Las guerras civiles romanas en Hispania. Una revisión histórica desde la Contestania, 199-294. Alicante: Diputación Provincial de Alicante-Universidad de Alicante.

Uroz Rodríguez, H. y Velaza, J. 2019. “Un fragmento de tabula de bronce procedente de la Colonia Libisosa Foroaugustana”. Zeitschrift für Papyrologie und Epigraphik 211, 310-312.

Uroz Sáez, J. 2012. La colonia romana de Libisosa y sus precedentes. En Carrasco, G. (coord.), La ciudad romana en Castilla-La Mancha, 87-130. Cuenca: Universidad de Castilla-La Mancha.

Uroz Sáez, J. y Poveda, A. M. 2008. Modelos romanos de integración territorial en el sur de Hispania Citerior. En Uroz Sáez, J., Coarelli, F. y Noguera, J. M. (eds.), Iberia e Italia: modelos romanos de integración territorial, 143-168. Murcia: Tabularium.

Uroz Sáez, J., Molina Vidal, J., y Poveda Navarro, A. M. 2002. El foro de Libisosa. Datos preliminares de una investigación en curso. En II Congreso de Historia de Albacete. Volumen I: Arqueología y Prehistoria, 245-251. Albacete: Instituto de Estudios Albacetenses.

Uroz Sáez, J., Molina Vidal, J., Poveda Navarro, A. M., y Márquez Villora, J. C. 2004. Aproximación al conjunto arqueológico y monumental de Libisosa (Cerro del Castillo, Lezuza, Albacete). En Investigaciones Arqueológicas en Castilla-La Mancha (1996-2002), 181-191. Toledo: Junta de Comunidades de Castilla-La Mancha.

Uroz Sáez, J., Poveda Navarro, A. M. y Márquez Villora, J. C. 2006. La puerta norte de Libisosa: cronología y arquitectura. En Schattner, Th. G. y Valdés, F. (eds.), Puertas de ciudades. Tipo arquitectónico y forma artística, 173-184. Toledo: Philipp von Zabern-Diputación Provincial de Toledo.

Uroz Sáez, J. y Uroz Rodríguez, H. 2016. La importancia de las vías de comunicación y Libisosa: ejército, comercio y romanización en su contexto arqueológico tardorrepublicano. En Carrasco, G. (coord.), Vías de comunicación romanas en Castilla-La Mancha, 151-176. Cuenca: Universidad de Castilla-La Mancha. 